\title{
New journal: Advanced Electrode Materials
}

\author{
Zheng Hu \\ School of Chemistry and Chemical Engineering, Nanjing University, Nanjing 210023, Jiangsu, China.
}

Correspondence to: Prof. Zheng Hu, School of Chemistry and Chemical Engineering, Nanjing University, Nanjing 210023, Jiangsu, China. E-mail: zhenghu@nju.edu.cn

How to cite this article: Hu Z. New journal: Advanced Electrode Materials. Adv Electr Mater 2021;1:1. https://dx.doi.org/10.20517/aem.2021.01

Received: 8 Jun 2021 Accepted: 8 Jun 2021 Available online: 21 Jun 2021

Academic Editor: Zheng Hu Copy Editor: Whitney Xu Production Editor: Xi-Jun Chen

Nowadays, a new round of technological revolution and industrial transformation is under accelerated evolution. New material science, energy technology, biotechnology, and next-generation information technology have become technical guarantees for mankind to meet global challenges and realize sustainable development. As a common concern for scientists worldwide, researches on improving the efficiency of energy conversion and storage, early diagnosis of cancer, environmental pollution monitoring and treatment, have become the frontier fields. The research hotspots include electrochemical batteries, solar cells, electrocatalysis and photocatalysis, biosensors, displays and flexible electronic devices. And electrode materials are the indispensable material basis for supporting the device performance. Therefore, through the innovation and cooperation of scientists and engineers in research fields of materials, chemistry, physics, biology, and electronics, the design, preparation, and application of advanced electrode materials would all be accelerated, and then promote the new technologies to realize the global dream of sustainable development of mankind.

Advanced Electrode Materials (AEM) is a new journal published by OAE Publishing Inc. AEM is an openaccess, peer-reviewed journal publishing high-impact research work from across the areas involving electrode materials and sciences, aiming to provide an interdisciplinary platform for premier and insightful research in the fields of energy, environment, electronics, biology, and engineering of electrically active materials. AEM will embrace all advances in electrode materials and their novel applications at the crosssection of advanced materials, encompassing state-of-the-art electrode materials, engineering of applied 
electrode materials, and innovation of next-generation electrodes.

AEM aims at publishing a set of article types, such as Original Articles, Review Articles, Short Communications, and Letters to the Editor.

$A E M$ is led by a group of Editors who are globally well-known, very active in their research fields, and rich of editorial experience across the topics covered by the journal. The Editor-in-Chief, Prof. Zheng Hu from Nanjing University (China), is responsible for the whole publication process of AEM. Five Associate Editors are on the board, including Prof. Shuhui Sun from Institut National de la Recherche Scientifique (Canada), Prof. Liangti Qu from Tsinghua University (China), Prof. Jong-Beom Baek from Ulasn National Institute of Science \& Technology (South Korea), Prof. Ulrich Stimming from Newcastle University (United Kingdom), and Prof. Yanwen Ma from Nanjing University of Posts and Telecommunications (China). They will assist the Editor-in-Chief in expediating the peer review process. We firmly believe that the experienced editorial team will strengthen the rapid dissemination of authors' most important, insightful, interdisciplinary and cutting-edge research achievements and will present highly efficient peer review and post-acceptance processes for our authors and reviewers.

\section{DECLARATIONS}

\section{Authors' contributions}

The author contributed solely to the article.

\section{Availability of data and materials}

Not applicable.

\section{Financial support and sponsorship}

None.

\section{Conflicts of interest}

The author declared that there are no conflicts of interest.

\section{Ethical approval and consent to participate}

Not applicable.

\section{Consent for publication}

Not applicable.

\section{Copyright}

(c) The Author(s) 2021. 